\title{
Atypical presentation of herpetic whitlow as dark brown vesicles in a hyperbilirubinemic patient
}

\author{
A. Shiyovich • L. Nesher
}

Received: 19 May 2014/ Accepted: 11 July 2014/Published online: 29 July 2014

(c) Springer-Verlag Berlin Heidelberg 2014

\section{Case presentation}

A 36-year old Caucasian female with a history of metastatic carcinoma of the ovary was hospitalized for a CTguided percutaneous biliary drain placement due to compression of the bile duct by metastases causing severe hyperbilirubinemia. Upon admission the patient mentioned lesions in the left index finger that appeared 12-14 days prior to admission as small tingling reddish vesicles which subsequently grew and darkened.

Physical examination was significant for severe jaundice and dark brown vesicular lesions in the left index finger without lymphangitis or lymphadenitis (Fig. 1).
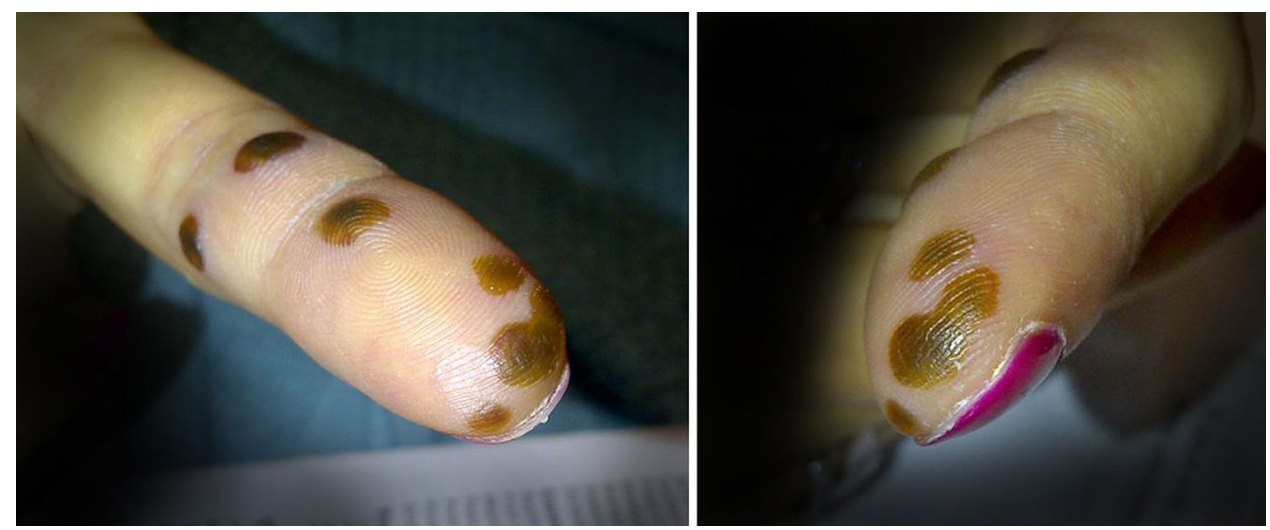

Fig. 1 Left index finger demonstrating dark colored raised vesicular lesions

\footnotetext{
A. Shiyovich $(\square)$

Medicine E Beilinson Hospital, Rabin Medical Center,

39 Jabotinski Street, 49100 Petah Tikva, Israel

e-mail: arthur.shiyovich@gmail.com

L. Nesher

Internal Medicine Division, Ben-Gurion University,

Soroka Medical Center, Beer Sheba, Israel
} 
Laboratory findings were: leukocyte count $=11,200$ / $\mathrm{mm}^{3}$; hemoglobin $=7.2 \mathrm{~g} / \mathrm{dL}$; platelets $65,000 / \mathrm{mm}^{3}$; creatinine $=0.6 \mathrm{mg} / \mathrm{dL} ; \mathrm{ALT}=170 \mathrm{IU} / \mathrm{ml} ; \mathrm{AST}=157 \mathrm{IU} /$ $\mathrm{ml}$; total bilirubin $=14.4 \mathrm{IU} / \mathrm{ml}$. One of the lesions was unroofed and a swab taken from the site for viral culture was reported back as HSV 1 infection. Herpetic whitlow is a painful infection that typically affects the fingers, caused by HSV-1 or HSV-2 $[1,2]$. Immunocompromised individuals (e.g., cancer) are at increased risk for infection. Clinical presentation includes erythema and small, clear vesicles initially formed individually; then these may coalesce and merge [3]. It is commonly misdiagnosed as a bacterial infection (cellulitis, paronychia or felon) [3].The atypical dark color in the current case results from the elevated bilirubin, which tends to stain bodily fluids. Although the disease is self-limiting (50\% recurrence rate) $[2,3]$, famciclovir or valacyclovir $[2,4]$ are often used by physicians.
This case highlights the challenging diagnosis that HSV infection of the hand can present, emphasizing the importance of knowledge of the various presentations in different patients.

Conflict of interest All authors report no conflict of interest.

\section{References}

1. Pintor E, Montilla $\mathrm{P}$, Catalán $\mathrm{P}$, Burillo A, Gargantilla $\mathrm{P}$, Herreros B. Recurrent infection in the left thumb. Infection. 2013;41: 1203-4.

2. Clark DC. Common acute hand infections. Am Fam Physician. 2003;68:2167-76.

3. Hoff NP, Gerber PA. Herpetic whitlow. CMAJ. 2012;184:E924.

4. Kesson AM. Use of aciclovir in herpes simplex virus infections. J Paediatr Child Health. 1998;34:9-13. 